\title{
Spectral Characteristics and Mapping of Rice Plants Using Multi-Temporal Landsat Data
}

\author{
I Wayan Nuarsa (Corresponding author) \\ Faculty of Agriculture, Udayana University \\ Kampus Bukit Jimbaran 80361, Bali-Indonesia \\ Tel: 62-361-703-602 E-mail: nuarsa@ymail.com
}

Fumihiko Nishio

Center for Environmental Remote Sensing, Chiba University

1-33 Yayoi-cho, Inage-ku, Chiba-shi 263-8522, Japan

Tel: 81-043-290-3836 E-mail: fnishio@faculty.chiba-u.jp

Chiharu Hongo

Center for Environmental Remote Sensing, Chiba University

1-33 Yayoi-cho, Inage-ku, Chiba-shi 263-8522, Japan

Tel: 81-043-290-3859 E-mail: hongo@faculty.chiba-u.jp

The research is financed by Japan Society for the Promotion of Science (JSPS) Ronpaku, Japan

\begin{abstract}
The visible band of Landsat ETM+ (Band 1, Band 2, and Band 3) showed a weak exponential relationship to rice age; however, the reflective infrared band of Landsat ETM+ (Band 4 and B5) and the entire vegetation index showed a strong exponential relationship to rice age. Rice Growth Vegetation Index (RGVI) developed in this study is the best vegetation index compared to existing vegetation indices. The relationship between rice age and RGVI has shown the highest determination coefficient $\left(\mathrm{R}^{2}\right)$ of 0.9045 . The RGVI then used to develop a model to rice plant mapping. Quantitative comparison of the rice plant area between analysis results and reference data showed a linear relationship, with the equation $\mathrm{y}=0.920 \mathrm{x}-3.841$ and $\mathrm{R}^{2}=0.971$, where $\mathrm{y}$ is the rice plant area of reference data, and $\mathrm{x}$ is the rice plant area of the analysis results of the Landsat ETM+. The standard error of this estimation was 43.04 ha.
\end{abstract}

Keyword: Rice plant, Mapping, Landsat ETM+, Remote sensing

\section{Introduction}

Rice is one of the world's major staple foods, and paddy rice fields account for approximately $15 \%$ of the world's arable land (IRRI 1993). In Indonesia, rice is one of the most important agricultural plants because rice is the main food consumed by Indonesians. Food security has long been an important political goal in Indonesia, and this goal is most commonly associated with rice self-sufficiency. In the mid-1980s, Indonesia briefly achieved 100\% self-sufficiency for rice; however, growth of rice production slowed in the 1990s, leading to an increase in imports and a lower self-sufficiency ratio. The rice self-sufficiency ratio has remained around $95 \%$ over the last two years, but it dropped below 90\% during the El Niño drought of 1998 (Bappenas 2002).

To determine the potential for rice self-sufficiency, rice production must be estimated. Conventionally, calculation of rice production is usually performed after harvest by collecting information from farmers. Another way rice production can be determined involves taking a rice grain from a sample area and then converting it to total of the harvest area. Both methods of rice production estimation are conducted during rice harvesting periods. These methods frequently takes a long time; therefore, it would be beneficial to gain information about rice production more quickly prior to harvest to make better judgments related to rice self-sufficiency and rice import. In addition, mapping of rice fields is important for management of water resources and estimation of gas emissions (Xiao et al. 2005) 
Rice plants have specific land cover properties. Rice land coverage changes during the rice life circle. In irrigated rice fields, almost all land coverage is dominated by water during the plantation period. As the rice ages, rice vegetation coverage grows and reaches a maximum (rice age $=2$ months) and then gradually decreases until harvest time (Shao et al. 2001, Nuarsa et al. 2005).

Satellite remote sensing has been widely applied and has been recognised as a powerful and effective tool in detecting land use and land cover changes (Ehlers et al. 1990, Meaille \& Wald 1990, Treitz et al. 1992, Westmoreland and Stow 1992, Harris and Ventura 1995, Yeh \& Li 1999, Patil et al. 2003). Satellite remote sensing provides both cost-effective multi-spectral and multitemporal data (Paine 1981). Satellite imagery has been used to monitor discrete land cover types by spectral classification. Additionally, it has been utilised to estimate biophysical characteristics of land surfaces via linear relationships with spectral reflectance or indices (Steininger 1996, Nuarsa et al. 2007).

Studies using satellite imaging to monitor rice growth have been reported (Shao et al. 1997, Kuroso et al. 1997, Le Toan at al. 1997, Panigrahy \& Sharma 1997, Oette et al. 2000, Shao et al. 2001, David et al. 2004). Some of this research has been used globally as along with moderate image resolution, such as National Oceanic and Atmospheric Administration Advanced Very High Resolution Radiometer (NOAA AVHRR) and Moderate Resolution Imaging Spectroradiometer (MODIS), to monitor rice fields (Panigrahy et al. 1992, Fang et al. 1998, Wataru et al. 2006, Xiao et al. 2005). However, the use of moderate and global spatial resolution of satellite imaging has been restricted, particularly in small rice areas because many types of land cover appear in one pixel, which reduces the accuracy of the assessment (Strahler et al. 2006). In contrast, utilisation of fine or medium spatial resolution of satellite images, especially in session plants, has been limited because fewer images are available during the 120-day rice growth period (Currey et al. 1987). Landsat ETM+ has a good temporal, spatial, and spectral resolution for rice monitoring. The revisit time of Landsat ETM+ is 16 days with a spatial resolution of $30 \mathrm{~m}$. Landsat ETM+ has six bands with the same pixel size, and it has become beneficial in the development of the algorithms for rice modelling (Christopher 2004).

The objectives of our study included the following: (1) to find out relationship between rice spectral and rice age; (2) to develop a rice growth vegetation index (RGVI); (3) to map rice distribution and its age; and (4) to quantitatively compare the rice plant area between the analysis result and reference data.

\section{Methodology}

\subsection{Description of the study area}

The study was conducted in the Tabanan Regency of the Province of Bali, Indonesia, centred at latitude $8^{\circ} 29^{\prime} 46^{\prime \prime} \mathrm{S}$ and longitude $115^{\circ} 29^{\prime} 48^{\prime \prime} \mathrm{E}$ (Figure 1). The Tabanan Regency was selected for the study area because Tabanan is the central production area of rice in Bali. The irrigated paddy rice area in Bali was not only planted by the rice but also with other session agriculture plants, such as corn and soybeans. Rice planting in Bali is coordinated by the social farmer organisation, namely Subak, and it is related to the management of water resources. Each Subak usually consist of around 150 - 300 ha of paddy rice. In each Subak, farmers plant rice at the same time; thus, identification of the agriculture rice area from space using remote sensing data, such as Lantsat ETM+, may be easier. This study involved the use of three Subaks in three different districts, including Bengkel Subak (Kediri district), Sungi Subak (Marga District), and Risaja Subak (Penebel District). Field observation was done at 9 station points (Table 1).

The elevation of the study area ranged from $30-290 \mathrm{~m}$ asl. All rice plants observed were of the Ciherang rice variety, with a life cycle of around 115 days and yields reaching 5.0 tons/ha.

\subsection{Landsat image data}

Landsat satellite images have 8 bands, including a thermal and a panchromatic band. In visible, near infrared and middle infrared regions, Landsat ETM+ has 30-m spatial resolution. However, in thermal and panchromatic regions, spatial resolutions are $60 \mathrm{~m}$ and $15 \mathrm{~m}$, respectively. This study used both visible and reflectance infrareds (Band-1 - 5 and band-7) of Landsat ETM+ (Table 2). Although the Landsat ETM+ used in this study had the SLC off, considerations of better spatial, spectral, and temporal resolution of these images made it relevant to use. With 16 days of temporal resolution, Landsat ETM+ was the ideal satellite image for rice monitoring because rice has a growth circle length of only 115 days.

The total of amount of time series images that could be collected in one rice growth circle was approximately six images at different acquisition dates. Some of the images could not be used due to cloud conditions or the appearance of SLC-off on station points, which caused a reduced availability of images. Fortunately, our study area was covered by two scenes of Landsat images in different paths. The Landsat images from two different 
years (2002 and 2005) used in this study are shown in Table 3. Landsat Images from 2005 were used for rice modelling, and in 2002, they were utilised to apply the model for rice plant distribution mapping.

\subsection{Data analysis}

\subsubsection{Radiometric corrections}

In temporal analysis of the remote sensing data, radiometric corrections are the important part of the image analysis. The digital number (DN) of the Landsat ETM+ at different acquisition dates was converted to the corrected digital number $(\mathrm{cDN})$ to eliminate the effect of the radiometric and atmospheric of images, so they had comparable values. In this study, we used a simple radiometric correction model introduced by Pons \& Solé-Sugrañes (1994). The form of the model is shown in the following equation:

(i) (if $250<\mathrm{cDN} \leq 318.3 ; \mathrm{cDN}=254$ ),

$$
C D N=1000 a\left(D N-K_{Z}\right) a^{2} /\left[\mu_{g} S_{0} e^{\left(-\tau_{0} / \mu_{0}\right)_{e}\left(-\tau_{0} / \mu_{W}\right)}\right]
$$

(ii) (if $\mathrm{cDN}>318.3 ; c D N=255$ ),

(iii) (if $\mu_{\mathrm{s}} \leq 0 ; \mathrm{Vc}=255$ ),

where $\mathrm{cDN}$ is the corrected digital number, $\mathrm{cDN}$ is the conversion of the effective reflectance to the common 8 -bit format of most image processors, and the output range of values was limited to between 0 and 255 . Note that $\mathrm{a}, \mathrm{K}_{1}, \mathrm{~S}_{0}$, and $\tau_{0}$ depend on the wavelength and have different values for each spectral band; $\mathrm{K}_{1}$ depends on each image because it is related to atmospheric conditions; $\mu_{0}$ and $\mu_{\mathrm{s}}$ depend on latitude, date, and time of the satellite pass; $\mu_{\mathrm{s}}$ depends on the slope and aspect of each pixel; $\mathrm{d}$ depends on the date of the satellite pass; and $\mu_{\mathrm{v}}$ depends on the sensor viewing angle. The parameter $\mu \mathrm{v}$ is 1 in most cases of Landsat-ETM images because $\mathrm{V}$ is 0 at the nadir and has small values on the rest of the image Pons \& Solé-Sugrañes (1994)

Practically, to apply the algorithm above we only needed a DEM with good quality (altimetrically and planimetrically) because the other parameters were known (e.g., $\mathrm{S}_{0}$ ) or could be inferred from images (e.g., $\mathrm{K}_{1}$ ). To avoid overcorrections and undercorrections on the ridges and channels and to account for local phenomena, it was important to use a DEM with a planimetric resolution comparable to the geometric resolution of the image. Naugle \& Lashlee (1992) showed that a DEM of $95 \mathrm{~m}$ can be insufficient for a Landsat TM image over rugged terrain. In this study, we derived a DEM from a topographical map with a spatial resolution of $30 \mathrm{~m}$. The value of parameters used in Equation 1 are shown in Table 3-4.

\subsubsection{Calculating the relationship between rice spectral and rice age}

Gathering cDN values from the Landsat pixels for the ninth site observation in of the entire rice growth period was the next step of our data analysis. In each acquisition date of the Landsat images, pixel samples were taken randomly in the ninth field observation site (Figure 1). The average value of the sample was used as a representative $\mathrm{cDN}$ value in that acquisition date. The relationship between rice age and rice spectral was done for both band spectral of Landsat ETM + and vegetation index with the following equation:

$$
\mathrm{y}=f(\mathrm{x})
$$

where $\mathrm{y}$ is the rice age, and $\mathrm{x}$ is the rice spectral. Several vegetation indexes that were evaluated in the study are shown in Table 5.

The relationship between rice age and both the $\mathrm{cDN}$ and vegetation index was evaluated using statistical parameters, including determination coefficient $\left(\mathrm{R}^{2}\right)$, level of significant value of analysis of variance (ANOVA), and standard error of estimation. The highest $\mathrm{R}^{2}$, lowest significant value of ANOVA, and lowest standard error of estimation of the relationship between rice age and Landsat spectral of rice was selected and used for rice plant mapping model. The $\mathrm{R}^{2}$ and standard error of estimation (SE) was calculated using the following equation:

$$
\begin{gathered}
\mathrm{R}^{2}=1-\frac{\left.\sum \mathrm{y}-\overline{\mathrm{y}}^{\prime}\right)^{2}}{\left.\sum \mathrm{y}-\mathrm{y}^{\prime}\right)^{2}} \\
\mathrm{SE}=\sqrt{\frac{\sum\left(\mathrm{y}-\mathrm{y}^{\prime}\right)^{2}}{\mathrm{n}}}
\end{gathered}
$$

\subsubsection{Development of a rice growth vegetation index (RGVI)}

Theoretically, rice plants in normal conditions are the same, like vegetation in general. Chlorophyll pigments that are present in leaves absorb red light. In the NIR portion, radiation is scattered by the internal spongy 
mesophyll leaf structure, which leads to higher values in NIR channels. This interaction between leaves and the light that strikes them is often determined by their different responses in the red and NIR portions of reflective light (Niel \& McVicar 2001). In contrast, absorption properties of the middle infrared band cause a low reflectance of rice plants in this channel (Lilliesand \& Kiefer 1994). In irrigated rice fields, especially in early transplanting periods, water environment plays an important role in rice spectral. The blue band of Landsat $\mathrm{ETM}+$ has good sensitivity to the existence of water; therefore, development of a rice growth vegetation index (RGVI) in this study used the B1, B3, B4, and B5 of Landsat ETM+ with the following equation:

$$
R G V I=\frac{(B 4+B 5+B 7)-(B 1+B 3)}{(B 4+B 5+B 7)}
$$

The equation above is then simplified as follow:

$$
\mathrm{RGVI}=1-\frac{(\mathrm{B} 1+\mathrm{B} 3)}{(\mathrm{B} 4+\mathrm{B} 5+\mathrm{B} 7)}
$$

where RGVI is the rice growth vegetation index, and B1, B3, B4, B5, and B7 refer to the band of Landsat $\mathrm{ETM}+$.

\subsubsection{Mapping rice plant and age}

Mapping distribution of rice plants used at least two Landsat images from sequential acquisition dates, with the following steps:

1. Converting the VI of the Landsat image to rice age using the best relationship equation between VI and rice age for both Landsat images from sequential acquisition dates. This procedure produces two rice plant maps, age $\mathrm{t}_{\mathrm{t}}$ and age $\mathrm{t}_{\mathrm{t}+\mathrm{n}}$.

2. Calculating the difference of rice plant age $(\Delta$ age $)$ with the equation below:

$$
\Delta \text { age }=\text { age }_{t+n}-\text { age }_{t}
$$

where $\Delta$ age, age $e_{t}$ and age $\mathrm{t}_{\mathrm{t}+\mathrm{n}}$ are maps of different rice plant ages from two sequential acquisition dates of Landsat imaging, rice age map in $\mathrm{t}$ acquisition date, rice age map in $\mathrm{t}+\mathrm{n}$ day acquisition date, respectively.

3. Calculating different days of sequential acquisition dates of Landsat image $(\Delta t)$.

4. Comparing $\Delta$ age and $\Delta \mathrm{t}$. The pixels that satisfy with the following equation are classified as rice plants, which include the standard error of calculation (SE).

$$
\Delta \text { age }-\mathrm{SE} \leq \Delta \mathrm{t} \leq \Delta \mathrm{age}+\mathrm{SE}
$$

Schematically, the research procedure used in this study is illustrated in the following flowchart.

\subsubsection{Quantitative evaluation of rice plant area}

Quantitative evaluation of rice plant area was performed by comparison of rice plant areas derived from analysis of Landsat to rice plant areas from the reference data in district level comparison. The reference data was obtained from the Statistic Center Agency of Tabanan Regency (BPS 2002). Rice plant area data were then plotted in a chart to determine their relationship, $\mathrm{R}^{2}$, and standard error of the estimation.

\section{Results and Discussion}

\subsection{Relationship between rice spectral and rice age}

Based on statistical analysis, exponential was the best equation form to show the relationship between rice plant spectral and rice age. Figure 3 shows an exponential relationship between rice age and rice cDN, whereas Figure 4 illustrates an exponential relationship between rice age and vegetation index. The best exponential relationship between rice age and rice $\mathrm{cDN}$ was provided by Band 5, followed by Band 4 and Band 7 of Landsat ETM+, with the determination coefficients $\left(\mathrm{R}^{2}\right)$ 0.8999, 0.8254, and 0.6847, respectively. Visible bands (Band 1, Band 2, and Band 3) showed weak relationships to rice plant age, with $\mathrm{R}^{2}$ values of $0.3325,0.0973$, and 0.3994 , respectively. However, using multiple bands of Landsat ETM+ as a vegetation index gave a better relationship between rice plant age and rice spectral than was obtained utilising a single band. All vegetation indexes evaluated in this study showed a strong relationship with rice age. The Rice Growth Vegetation Index (RGVI) that was developed in this study gives the best relationship, with $\mathrm{R}^{2}=0.9045$, followed by TVI, NDVI, SAVI, IPVI, DVI, and RVI, with $\mathrm{R}^{2}$ values of $0.8702,0.8259,0.8254,0.8250,0.7929$, and 0.6855 , respectively.

The advantage of using a vegetation index compared to use of a single band was to reduce the spectral data to a single number that is related to physical characteristics of vegetation (e.g., leaf area, biomass, productivity, 
photosynthetic activity, or percent cover) (Baret \& Guyot 1991, Huete 1988) while minimising the effect of internal (e.g., canopy geometry, and leaf and soil properties) and external factors (e.g., sun-target-sensor angles, and atmospheric conditions at the time of image acquisition) on the spectral data (Baret \& Guyot 1991, Huete and Warrick 1990, Huete \& Escadafal 1991).

\subsection{Rice plant mapping}

According to the statistical analysis of the relationship between rice spectral and rice age, RGVI was the best vegetation index to explain rice age due to the fact that it had the highest value of $\mathrm{R}^{2}$ as well as the lowest value of analysis of variance (Sig) and standard error of estimation (SE) (Table 6). Therefore, the exponential equation form of RGVI was used for rice plant mapping with the following equation:

$$
y=14.997 e^{2.4081 x}
$$

where $\mathrm{y}, \mathrm{e}$, and $\mathrm{x}$ are the rice age, the natural logarithm, and the RGVI, respectively.

Rice plant age was estimated using Equation 9 in two sequential acquisition dates of Landsat ETM+. The pixels that had the same difference values between predicted rice age in two sequential acquisitions dates, and the day distinction of two sequential acquisitions dates, were classified as a rice plant area after standard error of estimation was included (Equation 8).

Figure 5 and Table 7 show the distribution of the rice area resulting from classification process using Equation 8 . The map on Figure 5 not only describes the distribution of rice plants but also their age. This information is important to estimate the total amount of rice plants that can be harvested.

Rice fields in our study area had a narrow area mixed with other land uses, such as settlement, which is different from most characteristics of rice fields in other countries. The small area of rice plant is one of the challenges of mapping rice plants using remote sensing data. Therefore, use of Landsat ETM + data with a 30-m spatial resolution is more comfortable and appropriate in our study area than the use of a coarser spatial resolution of remote sensing data, such as MODIS and NOAA AVHRR data.

\subsection{Quantitative evaluation of Landsat-derived rice map}

Evaluation of Landsat ETM+ accuracy quantitatively for rice plant distribution mapping was performed by comparing the total area derived from Landsat ETM+ to the data released by the Statistic Center Agency. The agriculture department of the local government did not publish the spatial data for land that was being planted with rice; therefore, the study results were carried out using a district-level comparison. Table 8 shows the comparison of total rice area between analysis results of Landsat ETM + and reference data.

Based on Table 8, estimation results of total rice plants that were being planted in our study area is under-estimation for all districts, except for the Kerambitan district. For the districts of Selemadeg, Pupuan, Tabanan, Kediri, Marga, Penebel, and Baturoti, total of estimation area from the Landsat data was lower, in the amounts of $13.09 \%, 16.25 \%, 4.59 \%, 12.25 \%, 11.40 \%, 13.55 \%$ and $5.69 \%$, respectively, compared to the Statistic Center Agency data. However, in the Kerambitan district, estimation results from Landsat images were greater than the reference data (around $7.69 \%$ ). The under-estimation for almost all of the rice area obtained from Landsat image compared to the data from the local government caused by some of the Landsat rice pixel contained several objects besides rice plant. The mixed pixel can decrease the accuracy of the calculation (Strahler et al, 2006). Xiao et al. (2005) has carried out the same phenomena using MODIS data, and they found that the estimation result of the rice field area in the Southern China using MODIS imaging was lower than the references data.

The estimated rice area of Landsat ETM+ and reference data shows a strong relationship. The determination coefficient $\left(\mathrm{R}^{2}\right)$ was 0.971 using the equation $\mathrm{y}=0.920 \mathrm{x}-3.841$, where $\mathrm{y}$ was estimation area from the Landsat $\mathrm{ETM}+$, and $\mathrm{x}$ was the reference data (Figure 6). The standard error of the estimation was 43.04 ha.

\section{Conclusions}

The visible band of Landsat ETM+ (Band 1, Band 2, and Band 3) showed a weak exponential relationship to rice age; however, the reflective infrared band of Landsat ETM+ (Band 4 and B5) and the entire vegetation index showed a strong exponential relationship to rice age. Use of vegetation indexes to monitor and map rice plants gives better results than use of a single band of Landsat ETM+. A Rice Growth Vegetation Index (RGVI) was a new vegetation index developed in this study. RGVI is a better vegetation index to describe rice age than existing vegetation indexes. The relationship between rice age and RGVI has shown the highest determination coefficient $\left(\mathrm{R}^{2}\right)$ with the equation $y=14997 e^{24061 x}$, where $\mathrm{y}$ and $\mathrm{x}$ are the rice age and RGVI, respectively. Quantitative comparison of rice plants between analysis results and reference data showed a linear relationship with the 
equation $\mathrm{y}=0.920 \mathrm{x}-3.841$ and $\mathrm{R}^{2}=0.971$, where $\mathrm{y}$ was the rice plant area of reference data, and $\mathrm{x}$ is the rice plant area of the analysis results of the Landsat ETM+. The standard error of this estimation is 43.04 ha. Landsat ETM+ has good capabilities to monitor and map rice plants.

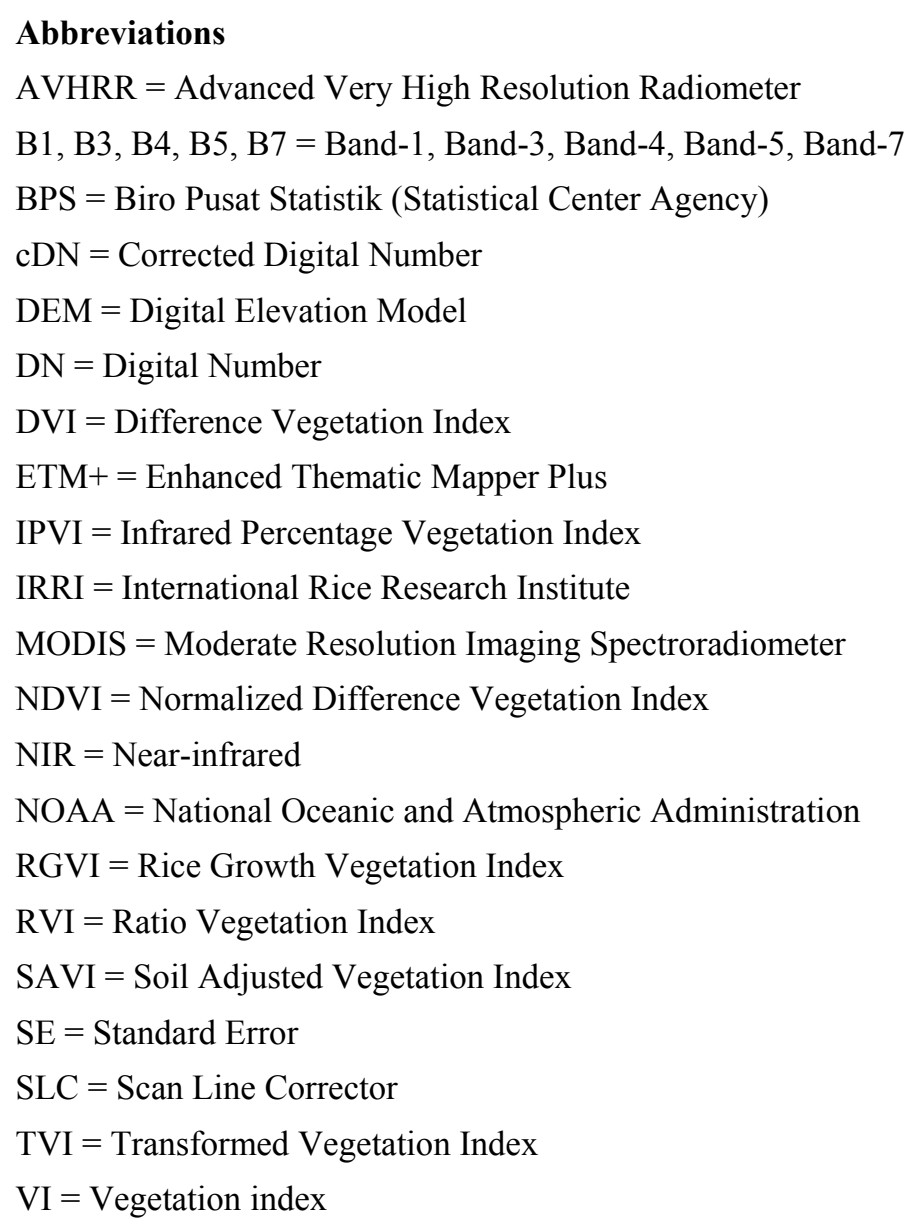

\section{References}

Bappenas. (2002). Does Indonesia Face a Food Security Time Bomb? Indonesian Food Policy Program. [Online] Available: http//:www.macrofoodpolicy.com (November 15, 2009).

BPS. (2003). Tabanan in Number. Annual Report, Statistic Center Agency of Tabanan Regency.

Chander, G., Markham, B.L., Dennis L. \& Helder, D.L. (2009). Summary of current radiometric calibration coefficients for Landsat MSS, TM, ETM+, and EO-1 ALI sensors. Remote Sensing of Environment, 113, 893-903.

David, D., Frolking, S. \& Li, C. (2004). Trends in Rice-Wheat Area in China. Field Crops Research, 87, 89-05.

Dozier, J. (1989). Spectral signature of Alpine snow cover from the Landsat Thematic Mapper, Remote Sensing of Environment, 28, 9-22.

Ehlers, M., Jadkowski, M. A., Howard, R. R. \& Brostuen, D. E. (1990). Application of SPOT data for regional growth analysis and local planning. Photogrammetric Engineering and Remote Sensing, 56, 175-180.

Fang, H., Wu, B., Liu, H. \& Huang, X. (1998). Using NOAA AVHRR and Landsat TM to estimate rice area year-by-year. International Journal of Remote Sensing, 19, 521-525.

Harris, P. M. \& Ventura, S. J. (1995). The integration of geographic data with remotely sensed imagery to improve classification in an urban area. Photogrammetric Engineering and Remote Sensing, 61, 993-998.

IRRI. (1993). 1993-1995 IRRI Rice Almanac. Manila7 International Rice Research Institute.

Kuroso, T., Fujita, M. \& Chiba, K. (1997). Monitoring of Rice Fields Using Multi-Temporal ERS-1 C-band SAR Data. International Journal of Remote Sensing, 14, 2953-2965. 
Le Toan, T., Ribbes, F., Floury, N., L., Kong, J., Korosu, T., and Fujita, M. (1997). Rice Crop Mapping and Monitoring Using ERS-1 Data Base on Experiment and Modeling Results. IEEE Transactions on Geosciences and Remote Sensing, 35, 41- 56.

Lillesand, T.M. \& Kiefer, R.W. (1994). Remote Sensing and Image Interpretation (3 ${ }^{\text {nd }}$ Ed.), New York: John Wiley and Sons.

Meaille, R. \& Wald, L. (1990). Using geographic information system and satellite imagery within a numerical simulation of regional urban growth. International Journal of Geographic Information Systems, 4, 445-456.

Naugle, B. I. \& Lashlee, J. D. (1992). Alleviating topographicinfluences on land-cover classifications for mobility and combat modeling, Photogrammetric Engineering and Remote Sensing, 58, 1217-1221.

Niel, T.G.V. \& McVicar, T.R. (2001). Remote Sensing of Rice-Based Irrigated Agriculture: A Review. [Online] Available: http://www.clw.csiro.au/publications/consultancy/2001/CRC-Rice-TRP11050101.pdf (15 December 2009).

Nuarsa, I.W. \& Nishio, F. (2007). Relationships between Rice Growth Parameters and Remote Sensing Data. International Journal of Remote Sensing and Earth Sciences, 4, 102-112.

Nuarsa I Wayan, Kanno, S., Sugimori, Y. \& Nishio, F. (2005). Spectral Characterization of Rice Field Using Multi-Temporal Landsat ETM+ Data. International Journal of Remote Sensing and Earth Sciences, 2, 65-71.

Oette, D. R., Warren B. C., Mercedes B., Maiersperger, T.K., \& Kennedy, R.E. (2000). Land Cover Mapping in Agricultural Setting Using Multiseasonal Thematic Mapper Data. Remote Sensing of Environment, 76, 139-155.

Paine, D.P. (1981). Aerial Photography and Image Interpretation for Resource Management. New York: John Wiley and Sons.

Panigrahy S, Parihar, J.S. \& Patel, N.K. (1992). Kharif rice acreage estimation in Orissa using NOAA-AVHRR data. Journal of the Indian Society of Remote Sensing, 20, 35-42.

Panigrahy, S. \& Sharma., S.A. (1997). Mapping of Crop Rotation Using Multidate Indian Remote Sensing Satellite Digital Data. ISPRS Journal of Photogrammetry \& Remote Sensing, 52, 85-91.

Pons, X. \& Solé-Sugrañes, L. (1994). A simple radiometric correction model to improve automatic mapping of vegetation from multispectral satellite data. Remote Sensing of Environment, 48, 191-204.

Shao, Y., Fan, X., Liu, H., Xiao, J., Ross, S., Brisco, B., Brown, R. \& Staples, G. (2001). Rice Monitoring and Production Estimation Using Multitemporal RADARSAT. Journal of Remote Sensing for Environment, 76, $310-325$.

Shao, Y., Wang, C., Fan, X., \& Liu, H. (1997). Evaluation of SAR image for Rice Monitoring and Land Cover Mapping. In Presented at Geomatics in Era of RADARSAT, Ottawa, Canada.

Steininger, M. K. (1996). Tropical secondary forest regrowth in the Amazon: age, area and change estimation with Thematic Mapper data. International Journal of Remote Sensing, 17, 9-27.

Strahler, A. H., Boschetti, L., Foody, G.M., Friedl, M.A., Hansen, M.C., Herold, M., Mayaux, P., Morisette, J.T., Stehman, S.V. \& Woodcock, C.E. (2006). Global Land Cover Validation: Recommendations for Evaluation and Accuracy Assessment of Global Land Cover Maps. Office for Official Publications of the European Communities. [Online] Available: http://wgcv.ceos.org/docs/plenary/wgcv26/GlobalLandCoverValidation_JeffMorisette.pdf (July 25, 2009.)

Treitz, P. M., Howard, P. J. \& Gong, P. (1992). Application of satellite and GIS technologies for land-cover and land-use mapping at the rural-urban fringe: a case study. Photogrammetric Engineering and Remote Sensing, 58, 439-448.

Wataru, T, Taikan, O., and Yoshifumi, Y. (2006). Investigating an integrated approach on rice paddy monitoring over Asia with MODIS and AMSR-E. Proceedings of the Conference of the Remote Sensing Society of Japan, 40, 173-174.

Westmoreland, S. and Stow, D. A. (1992). Category identification of changed land-use polygons in an integrated image processing/geographic information system. Photogrammetric Engineering and Remote Sensing, 58, $1593-1599$.

Xiao, X., Boles, S., Liu, J., Zhuang, D., Frolking, S., Li, C., Salas, W. \& Moore, B. (2005). Mapping paddy rice agriculture in southern China using multi-temporal MODIS images. Remote Sensing of Environment, 95, $480-492$. 
Table 1. Description of the field observation location

\begin{tabular}{|c|c|c|c|c|c|c|}
\hline \multirow{2}{*}{$\begin{array}{l}\text { Site } \\
\text { Code }\end{array}$} & \multirow{2}{*}{$\begin{array}{c}\text { Site } \\
\text { Name }\end{array}$} & \multicolumn{2}{|c|}{ Coordinate } & \multirow{2}{*}{$\begin{array}{l}\text { Elevation } \\
\text { (m asl) }\end{array}$} & \multirow{2}{*}{$\begin{array}{c}\text { Plantation } \\
\text { Date }\end{array}$} & \multirow{2}{*}{$\begin{array}{c}\text { Rice } \\
\text { Variety }\end{array}$} \\
\hline & & $X$ & Y & & & \\
\hline K1 & Kediri-1 & 289310 & 9048966 & 46 & 12-Jun-2005 & Ciherang \\
\hline $\mathrm{K} 2$ & Kediri-2 & 288746 & 9049668 & 38 & 23-May-2005 & Ciherang \\
\hline K3 & Kediri-2 & 289833 & 9050236 & 52 & 8-Jun-2005 & Ciherang \\
\hline M1 & Marga-1 & 297438 & 9056641 & 168 & 15-Jul-2005 & Ciherang \\
\hline M2 & Marga-2 & 297777 & 9056203 & 163 & 13-Jul-2005 & Ciherang \\
\hline M3 & Marga-3 & 298158 & 9057479 & 171 & 7-Jul-2005 & Ciherang \\
\hline $\mathrm{P} 1$ & Penebel-1 & 292220 & 9064219 & 287 & 20-Jul-2005 & Ciherang \\
\hline $\mathrm{P} 2$ & Penebel-2 & 291817 & 9063737 & 266 & 24-Jul-2005 & Ciherang \\
\hline P3 & Penebel-3 & 292487 & 9063358 & 272 & 27-Jul-2005 & Ciherang \\
\hline
\end{tabular}

Table 2. Spectral ranges and spatial resolutions of Landsat 7 ETM+ bands

\begin{tabular}{clcc}
\hline $\begin{array}{c}\text { Band } \\
\text { number }\end{array}$ & Band divisions & $\begin{array}{c}\text { Spectral range } \\
(\mu \mathrm{m})\end{array}$ & $\begin{array}{c}\text { Spatial } \\
\text { resolution }(\mathrm{m})\end{array}$ \\
\hline 1 & Blue & $0.45-0.515$ & 30 \\
2 & Green & $0.525-0.605$ & 30 \\
3 & Red & $0.63-0.690$ & 30 \\
4 & Near-infrared & $0.75-0.90$ & 30 \\
5 & Mid-infrared & $1.55-1.75$ & 30 \\
7 & Mid-infrared & $2.09-2.35$ & 30 \\
\hline
\end{tabular}

Table 3. Value of $\tau_{0}^{(1),} \mathrm{S}_{0}^{(2)}$, and a ${ }^{(3)}$ for every spectral Landsat Band

\begin{tabular}{cccc}
\hline Band & $\tau_{0}$ & $\mathrm{~S}_{0}\left(\mathrm{Wm}^{-2} \mu \mathrm{m}^{-1}\right)$ & $\mathrm{a}$ \\
\hline ETM1 & 0.5 & 1997 & 0.7757 \\
ETM2 & 0.3 & 1812 & 0.7957 \\
ETM3 & 0.25 & 1533 & 0.6192 \\
ETM4 & 0.20 & 1039 & 0.9655 \\
ETM5 & 0.125 & 230.8 & 0.1257 \\
ETM7 & 0.075 & 84.9 & 0.0437 \\
\hline
\end{tabular}

Sources: (1) Dozier (1989); (2) Chander et al. (2009); (3) our image with calculation

Table 4. Value of $\mathrm{d}^{(1)} \mu_{0}{ }^{(2)}$, and $\mathrm{K}_{1}{ }^{(3)}$ for every acquisition date of Landsat ETM+

\begin{tabular}{|c|c|c|c|c|c|c|c|c|c|c|c|}
\hline \multirow{2}{*}{ Acquisition date } & \multirow{2}{*}{ Path } & \multirow{2}{*}{ Row } & \multirow{2}{*}{ DOY } & \multirow{2}{*}{ d } & \multirow{2}{*}{$\mu_{0}$} & \multicolumn{6}{|c|}{$\mathrm{K}_{1}$} \\
\hline & & & & & & ETM1 & ETM2 & ETM3 & ETM4 & ETM5 & ETM7 \\
\hline 26 April 2002 & 116 & 66 & 116 & 1.00626 & 0.79414 & 51 & 31 & 23 & 20 & 17 & 11 \\
\hline 21 May 2002 & 166 & 66 & 141 & 1.01210 & 0.75100 & 53 & 32 & 22 & 23 & 19 & 14 \\
\hline 7 July 2005 & 117 & 66 & 188 & 1.01669 & 0.71514 & 52 & 34 & 22 & 25 & 21 & 11 \\
\hline 1 August 2005 & 116 & 66 & 213 & 1.01497 & 0.74624 & 50 & 31 & 23 & 19 & 16 & 12 \\
\hline 17 August 2005 & 116 & 66 & 229 & 1.01244 & 0.78085 & 53 & 33 & 23 & 22 & 18 & 13 \\
\hline 24 August 2005 & 117 & 66 & 236 & 1.01103 & 0.80312 & 55 & 35 & 24 & 23 & 15 & 10 \\
\hline 4 October 2005 & 116 & 66 & 277 & 1.00033 & 0.88006 & 54 & 34 & 24 & 21 & 17 & 12 \\
\hline 12 November 2005 & 117 & 66 & 316 & 0.98983 & 0.90081 & 52 & 31 & 22 & 24 & 21 & 11 \\
\hline
\end{tabular}

Sources: (1) Chander et al (2009); (2) our image with calculation; (3) DN of our image. DOY is day of year 
Table 5. Several existing vegetation indices used in the study

\begin{tabular}{|c|c|c|}
\hline No & Vegetation Index & Formula \\
\hline 1 & Normalized Difference Vegetation Index (NDVI) & $N D V=\frac{n t r-r}{n t r+r}$ \\
\hline 2 & Ratio Vegetation Index (RVI) & $R V t=\frac{n t r}{r}$ \\
\hline 3 & Infrared Percentage Vegetation Index (IPVI) & $t P V I=\frac{n l r}{n l r+r}$ \\
\hline 4 & Difference Vegetation Index (DVI) & $D V I=n i r-r$ \\
\hline 5 & Transformed Vegetation Index (TVI) & $T V=\frac{100}{\sqrt{\frac{m i r-r}{n t r+r}+0.5}}$ \\
\hline 6 & Soil Adjusted Vegetation Index (SAVI) & $S A V I=\frac{(1+b)(n n-r)}{n n r^{2}+r+L}$ \\
\hline
\end{tabular}

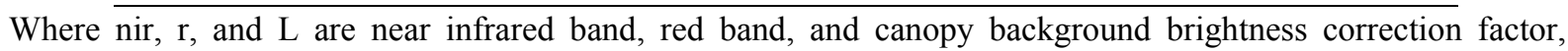
respectively.

Table 6. Value of determination coefficient, significant and standard error of relationship between rice spectral and rice age

\begin{tabular}{lrrr}
\hline Rice Spectral & $\mathrm{R}^{2}$ & Sig & SE \\
\hline cD1 & 0.3325 & 0.081 & 0.787 \\
cD2 & 0.0973 & 0.380 & 0.915 \\
cD3 & 0.3994 & 0.050 & 0.746 \\
cD4 & 0.8254 & 0.000 & 0.402 \\
cD5 & 0.8999 & 0.000 & 0.305 \\
cD7 & 0.6847 & 0.003 & 0.541 \\
NDVI & 0.8259 & 0.000 & 0.402 \\
RVI & 0.6855 & 0.003 & 0.540 \\
IPVI & 0.8250 & 0.000 & 0.403 \\
DVI & 0.7929 & 0.001 & 0.438 \\
TVI & 0.8702 & 0.000 & 0.347 \\
SAVI & 0.8254 & 0.000 & 0.402 \\
RGVI & 0.9045 & 0.000 & 0.297 \\
\hline
\end{tabular}

Table 7. Rice plant area of analysis results in each district

\begin{tabular}{lrr}
\hline District & nPixel & Area (ha) \\
\hline Kerambitan & 6701 & 603.09 \\
Selemadeg & 7812 & 703.08 \\
Pupuan & 884 & 79.56 \\
Tabanan & 2152 & 193.68 \\
Kediri & 5762 & 518.58 \\
Marga & 3091 & 278.19 \\
Penebel & 1585 & 142.65 \\
Baturiti & 2149 & 193.41 \\
\hline
\end{tabular}


Table 8. Comparison in district levels of rice area between analysis result of Landsat ETM+ and reference data

\begin{tabular}{lrrr}
\hline District & $\begin{array}{r}\text { Analysis } \\
\text { Result (ha) }\end{array}$ & $\begin{array}{r}\text { Reference } \\
\text { data (ha) }\end{array}$ & $\begin{array}{r}\text { Difference } \\
\text { (\%) }\end{array}$ \\
\hline Kerambitan & 603.09 & 560 & $7.69 \%$ \\
Selemadeg & 703.08 & 809 & $-13.09 \%$ \\
Pupuan & 79.56 & 95 & $-16.25 \%$ \\
Tabanan & 193.68 & 203 & $-4.59 \%$ \\
Kediri & 518.58 & 591 & $-12.25 \%$ \\
Marga & 278.19 & 314 & $-11.40 \%$ \\
Penebel & 142.65 & 165 & $-13.55 \%$ \\
Baturiti & 193.41 & 242 & $-20.08 \%$ \\
\hline
\end{tabular}

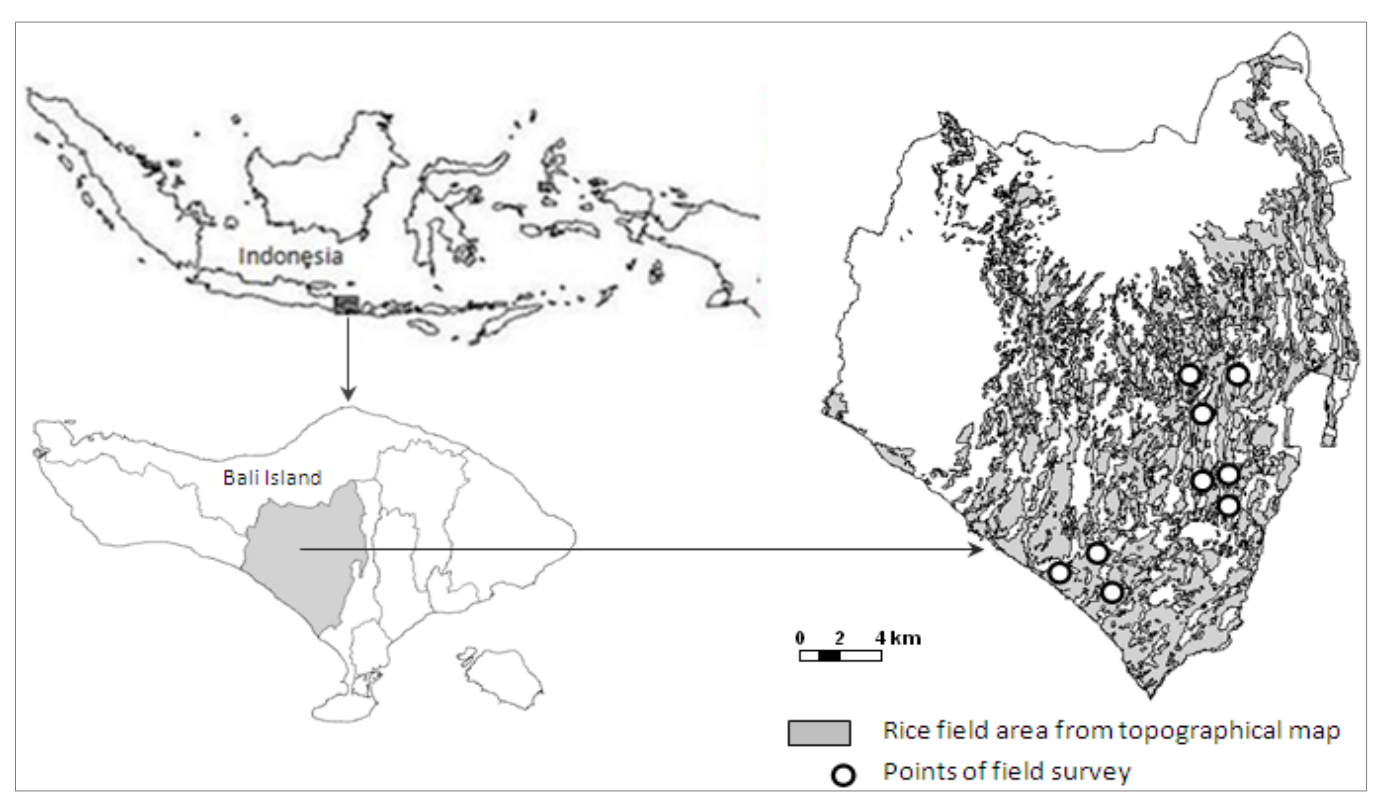

Figure 1. Location map of the study area 


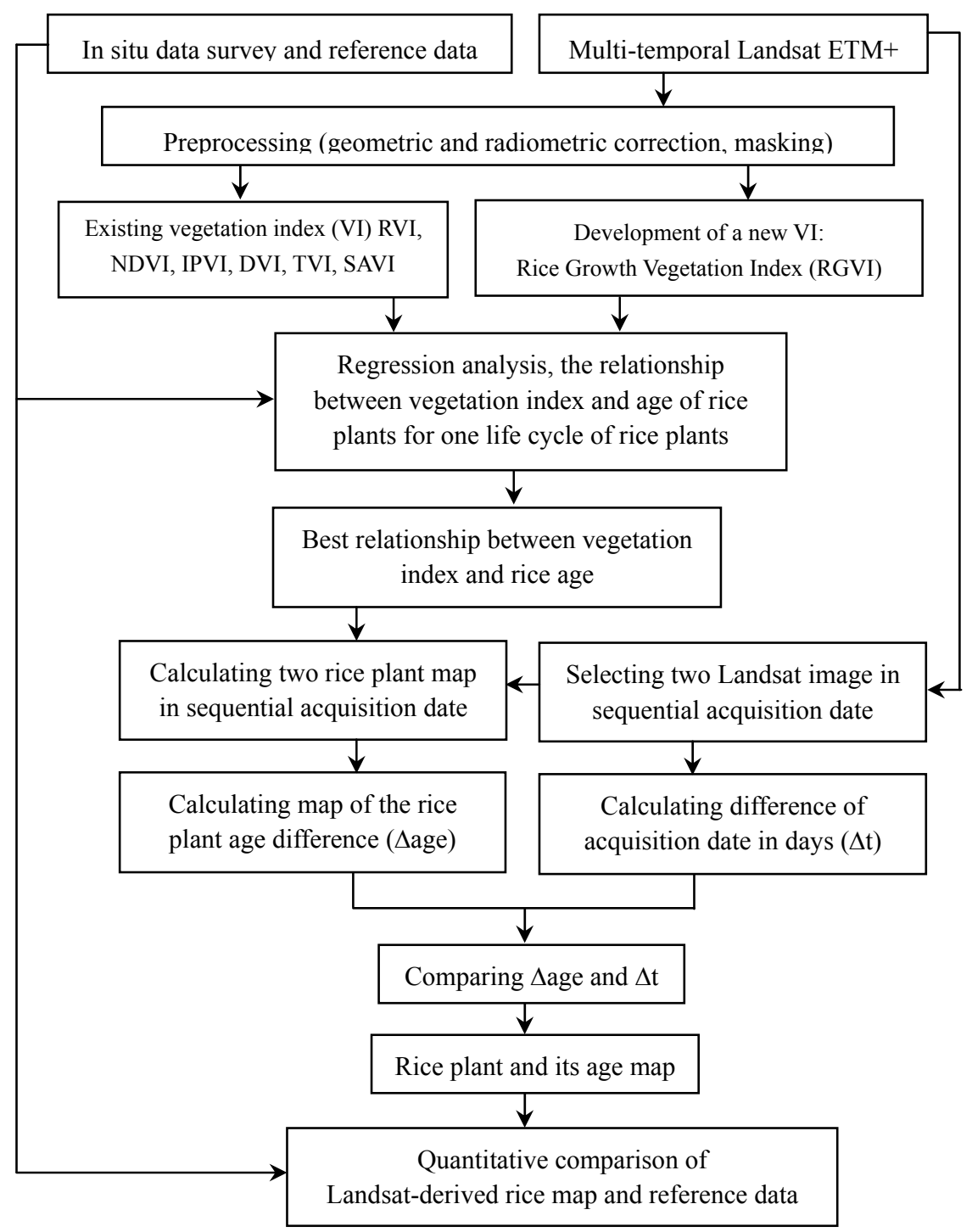

Figure 2. Data analysis procedure used in this study 

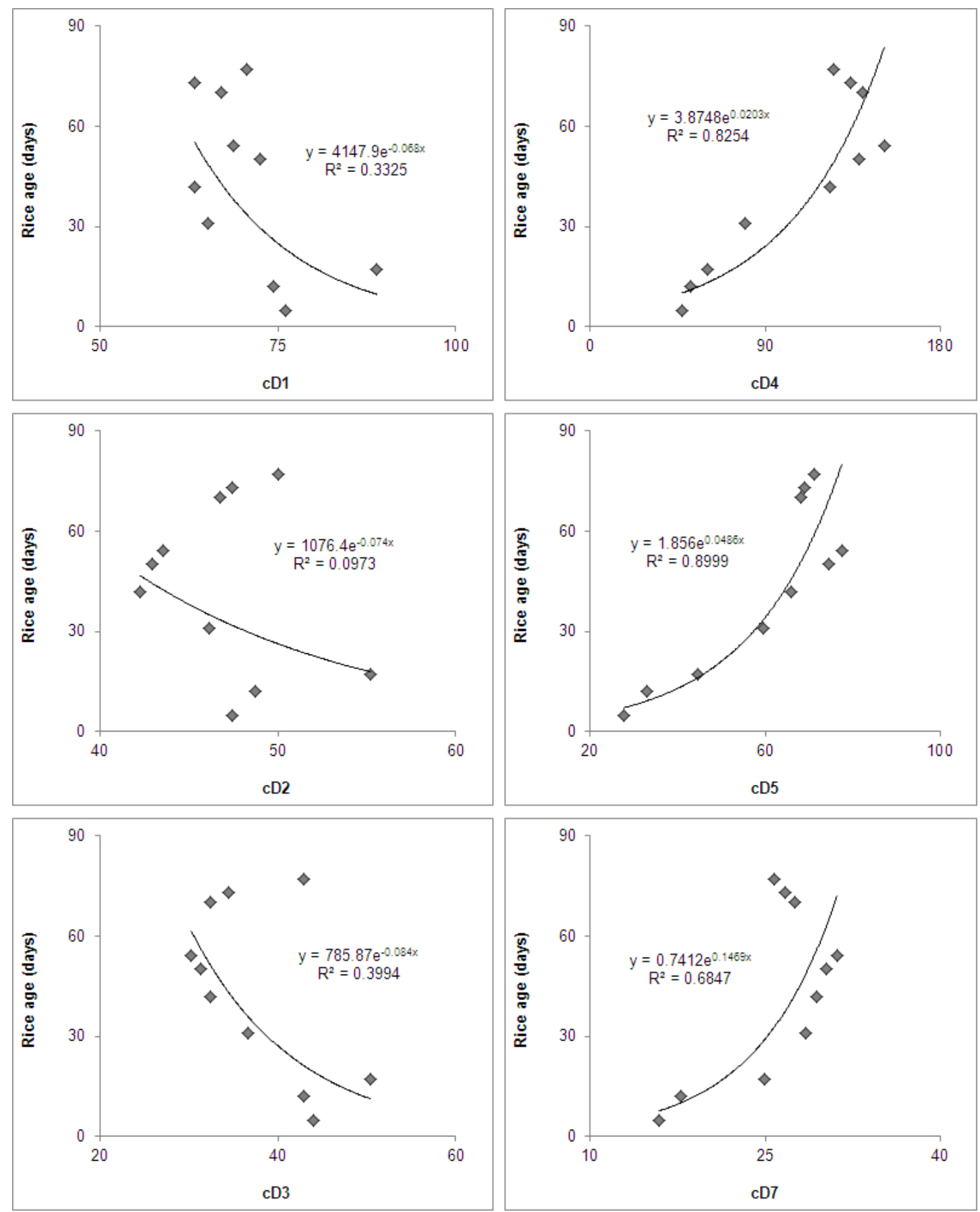

Figure 3. Relationship between rice cDN of Landsat ETM + and rice age 

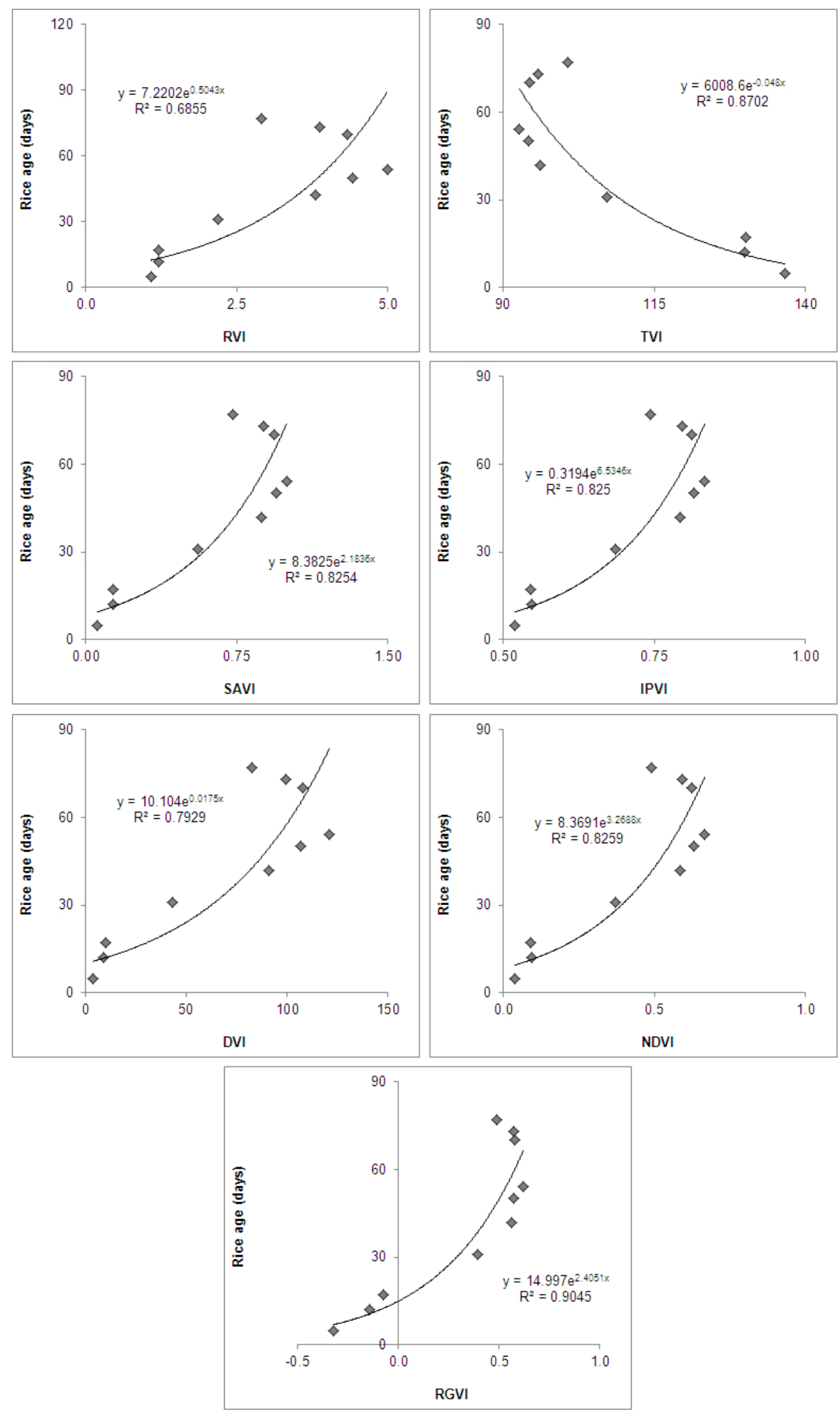

Figure 4. Relationship between rice vegetation index and rice age 


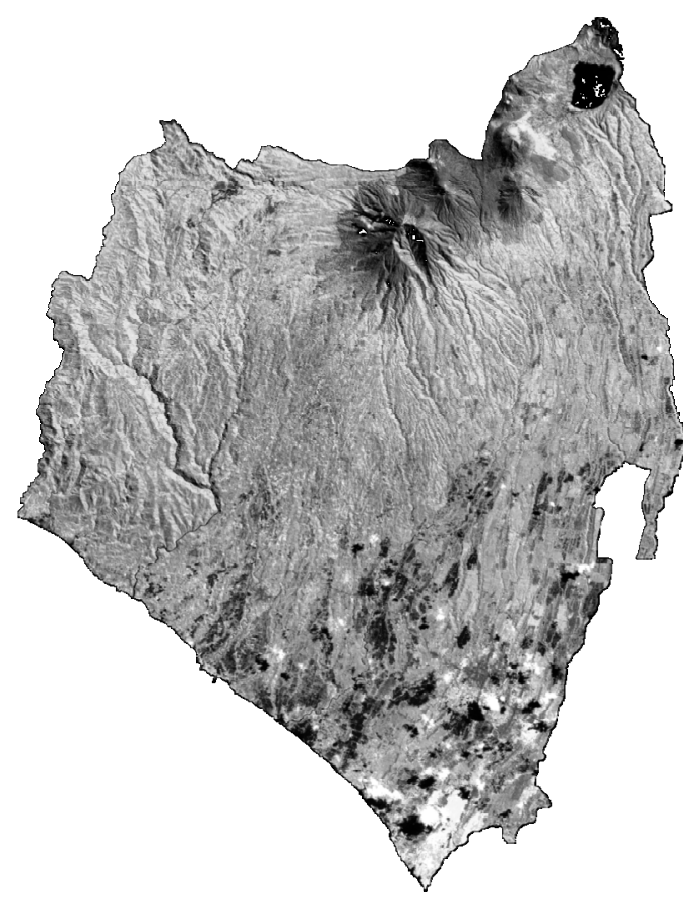

(a)

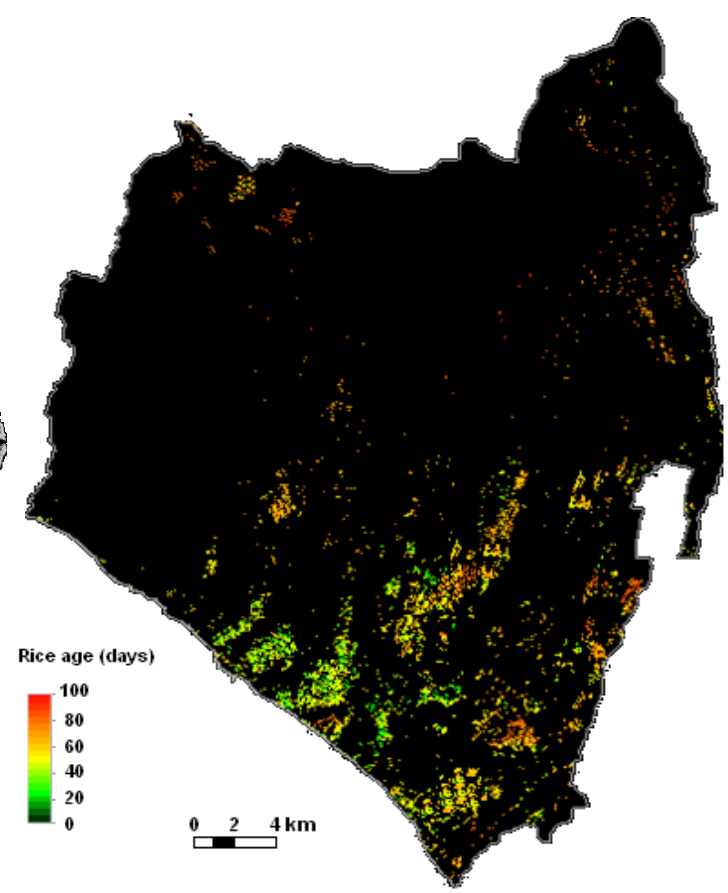

(b)

Figure 5. Rice plant distribution map of the study area from the analysis of Landsat ETM+ data (b) and false colour composite of Landsat ETM+ (a)

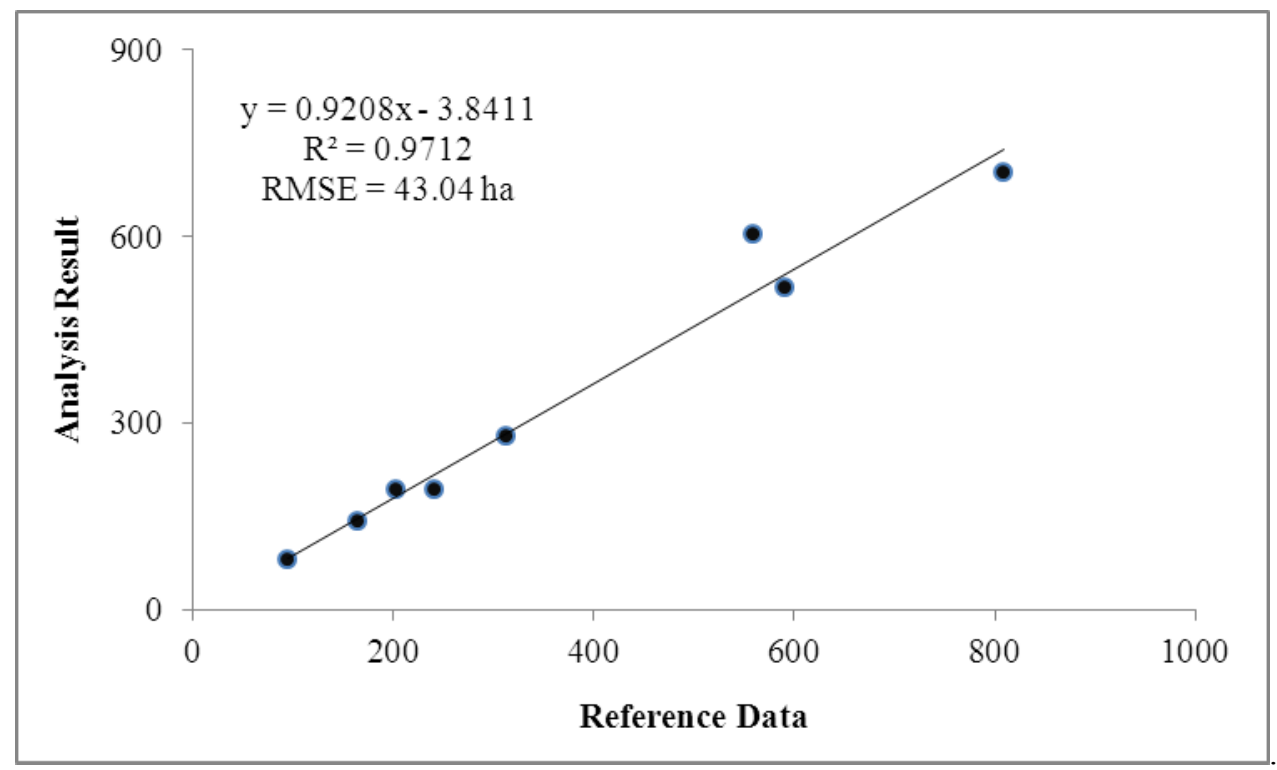

Figure 6. District-level comparison of the rice area from the Landsat ETM+ and the data from the local government 